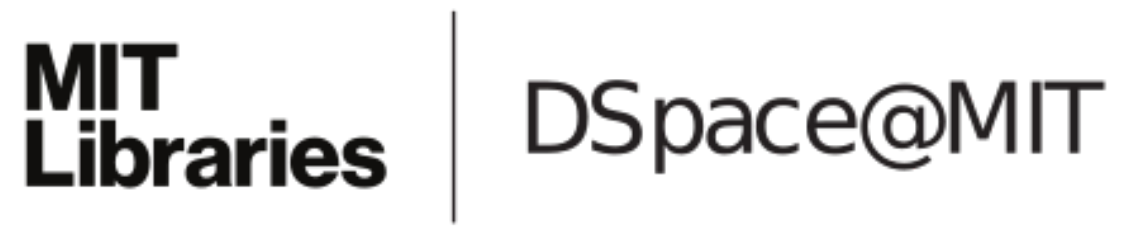

\author{
MIT Open Access Articles
}

Short Cationic Peptide Derived from Archaea with Dual Antibacterial Properties and Anti-Infective Potential

The MIT Faculty has made this article openly available. Please share how this access benefits you. Your story matters.

As Published: 10.1021/acsinfecdis.9b00073

Publisher: American Chemical Society (ACS)

Persistent URL: https://hdl.handle.net/1721.1/136219

Version: Author's final manuscript: final author's manuscript post peer review, without publisher's formatting or copy editing

Terms of Use: Article is made available in accordance with the publisher's policy and may be subject to US copyright law. Please refer to the publisher's site for terms of use. 


\title{
Infectious

\section{Short Cationic Peptide Derived from Archaea with Dual Antibacterial Properties and Anti-Infective Potential}

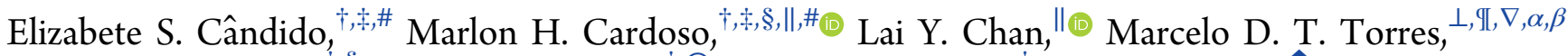 \\ Karen G. N. Oshiro, ${ }^{\ddagger} \S^{\circ}$ William F. Porto, $\stackrel{\ddagger}{\ddagger}$ Suzana M. Ribeiro, ${ }^{\ddagger}$ Evan F. Haney,

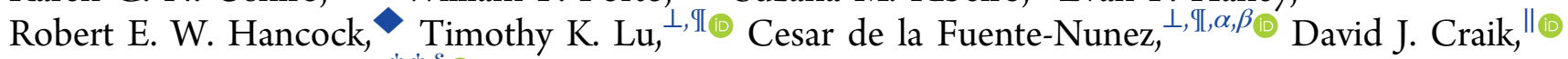 \\ and Octávio L. Franco $*, \dagger,+, \S_{(0)}$
}
†Centro de Análises Proteômicas e Bioquímicas, Pós-Graduação em Ciências Genômicas e Biotecnologia, Universidade Católica de Brasília, SGAN 916 Módulo B, Asa Norte, Brasília, Distrito Federal 70790160, Brazil
${ }^{\ddagger}$ S-Inova Biotech, Programa de Pós-Graduação em Biotecnologia, Universidade Católica Dom Bosco, Avenida Tamandaré 6000, Campo Grande, Mato Grosso do Sul 79117900, Brazil
${ }^{\S}$ Programa de Pós-Graduação em Patologia Molecular, Faculdade de Medicina, Universidade de Brasília, Campus Darcy Ribeiro, Asa Norte, Brasília, Distrito Federal 70910900, Brazil
"Institute for Molecular Bioscience, The University of Queensland, 306 Carmody Road, Brisbane, Queensland 4072, Australia
${ }^{\perp}$ Synthetic Biology Group, MIT Synthetic Biology Center; The Center for Microbiome Informatics and Therapeutics; Research Laboratory of Electronics, Department of Biological Engineering, and Department of Electrical Engineering and Computer Science, Massachusetts Institute of Technology, Cambridge, Massachusetts 02139, United States of America
II Broad Institute of MIT and Harvard, Cambridge, Massachusetts 02139, United States of America
${ }^{\nabla}$ Centro de Ciências Naturais e Humanas, Universidade Federal do ABC, Santo André, São Paulo 09210170, Brazil
OPorto Reports, Brasília, Distrito Federal 70790160, Brazil
Centre for Microbial Diseases and Immunity Research, University of British Columbia, Vancouver, British Columbia V6T 1Z4, Canada

\begin{abstract}
Bacterial biofilms and associated infections represent one of the biggest challenges in the clinic, and as an alternative to counter bacterial infections, antimicrobial peptides have attracted great attention in the past decade. Here, ten short cationic antimicrobial peptides were generated through a sliding-window strategy on the basis of the 19amino acid residue peptide, derived from a Pyrobaculum aerophilum ribosomal protein. PaDBS1R6F10 exhibited antiinfective potential as it decreased the bacterial burden in murine Pseudomonas aeruginosa cutaneous infections by more than 1000-fold. Adverse cytotoxic and hemolytic effects were not detected against mammalian cells. The peptide demon-
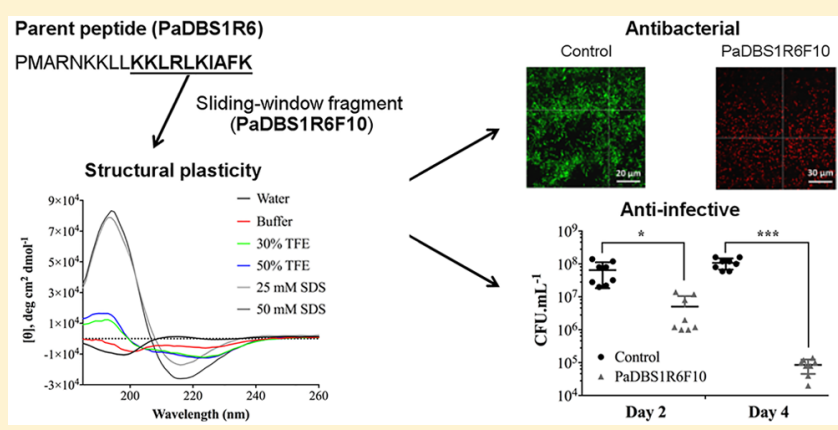
strated structural plasticity in terms of its secondary structure in the different environments tested. PaDBS1R6F10 represents a promising antimicrobial agent against bacteria infections, without harming human cells.
\end{abstract}

KEYWORDS: antimicrobial peptide, biofilm, cutaneous infection, CD spectroscopy

$\mathrm{T}$ he high incidence of drug-resistant bacterial and biofilmrelated infections currently represents a global health concern, demanding an urgent search for new antimicrobial strategies. ${ }^{1}$ Interestingly, despite recent efforts aimed at eradicating biofilm-related infections, only a few new antimicrobial drugs are specially aimed at biofilms. ${ }^{2}$ Moreover, the resistance associated with bacterial biofilms imposes numerous challenges for the use of conventional antimicrobials to treat these infections.

Natural antimicrobial peptides (AMPs) represent a promising alternative therapy for the treatment of drug-resistant infections. These molecules present high structural diversity and broad-spectrum antimicrobial activity. ${ }^{3}$ Natural AMPs have been explored with the aim of making a new generation of synthetic bioinspired molecules, which are a promising option for the engineering of more active and multifunctional drugs. ${ }^{4}$ The use of rational design approaches has enabled the generation of improved AMP synthetic analogues, reducing the limitations and increasing the advantages of these natural molecules. ${ }^{5}$ In particular, short AMPs represent attractive

Received: February 20, 2019

Published: April 24, 2019 
targets for drug development as their size makes them less expensive to synthesize compared to larger peptides.

In a previous work, our research group described a novel computational tool to insert patterns into primary sequences for designing AMPs, denominated the Joker algorithm. ${ }^{6}$ In that work, Porto et al. ${ }^{6}$ identified the $\alpha$-helical pattern (KK[ILV]$\mathrm{x}(3)$ [AILV]) from 248 helical AMPs deposited in the Antimicrobial Peptide Database (APD). ${ }^{7}$ Further, peptide sequences matching this $\alpha$-helical pattern were obtained from the National Center for Biotechnology Information (NCBI) non-redundant (NR) protein database. As a result, a Pyrobaculum aerophilum ribosomal protein fragment (L39e, MARNKPLGKKLRLAAAFK) was identified and used as template sequence for Joker, aiming at sequence optimization. A total of nine variants were generated (PaDBS1R1-R9), and the highest antibacterial activity was reported for PaDBS1R6, which was recently characterized as a selective antibacterial peptide against Gram-negative bacteria. ${ }^{8}$ Thus, considering the promising antibacterial potential of PaDBS1R6 and the pharmaceutical interest in short bioactive peptides, here, we applied a sliding-window strategy to generate fragments containing 10-amino acid residues, named PaDBS1R6F1F10. On the basis of our initial analyses, the fragment PaDBS1R6F10 was the most effective peptide at inhibiting bacterial growth. We therefore selected this short cationic peptide for detailed antibacterial, antibiofilm, anti-infective, hemolytic, and cytotoxic assays, as well as secondary structure characterization.

The results for the initial screening for antibacterial activities against a $P$. aeruginosa bioluminescent strain using the fragments PaDBS1R6F1 to F10 are summarized in Table 1, revealing the highest activity for PaDBS1R6F10 (minimal inhibitory concentration (MIC) $=20 \mu \mathrm{M}$ ).

Table 1. Antibacterial Properties of 10 Sliding-Window Fragments from PaDBS1R6 against Bioluminescent P. aeruginosa $\mathrm{H} 1001$

\begin{tabular}{clc} 
peptides & \multicolumn{1}{c}{ sequence } & MIC $^{a}(\mu \mathrm{M})$ \\
\hline PaDBS1R6F1 & PMARNKKLLK & $>100$ \\
PaDBS1R6F2 & MARNKKLLKK & $>100$ \\
PaDBS1R6F3 & ARNKKLLKKL & $>100$ \\
PaDBS1R6F4 & RNKKLLKKLR & $>100$ \\
PaDBS1R6F5 & NKKLLKKLRL & $>100$ \\
PaDBS1R6F6 & KKLLKKLRLK & $>100$ \\
PaDBS1R6F7 & KLLKKLRLKI & $>100$ \\
PaDBS1R6F8 & LLKKLRLKIA & 80 \\
PaDBS1R6F9 & LKKLRLKIAF & 40 \\
PaDBS1R6F10 & KKLRLKIAFK & 20 \\
\hline
\end{tabular}

${ }^{a}$ MIC: minimal inhibitory concentration.

This peptide was tested further against Gram-positive and -negative bacteria commonly reported in nosocomial infections, ${ }^{9}$ using the broth dilution method for MIC determination. ${ }^{10}$ PaDBS1R6F10 was more effective at inhibiting Escherichia coli (ATCC 25922 and the clinical strain $\mathrm{KpC}+001812446$; $\mathrm{KpC}$ is Klebsiella pneumoniae carbapenemase) and Enterococcus faecalis (ATCC19433) strains (Table $2)$. At the maximum concentration tested (32 $\mu \mathrm{M})$, PaDBS1R6F10 was active against $P$. aeruginosa and Staphylococcus aureus.

In the literature, $P$. aeruginosa strains have been highlighted as opportunistic nosocomial pathogens in immunocompro-
Table 2. Antibacterial, Cytotoxic, and Hemolytic Properties of PaDBS1R6F10 ${ }^{a}$

\begin{tabular}{|c|c|}
\hline microorganism & $\operatorname{MIC}(\mu \mathrm{M})$ \\
\hline E. coli ATCC 25922 & 16 \\
\hline E. coli $\mathrm{KpC}+001812446$ & $16-32$ \\
\hline E. coli BL21 & 4 \\
\hline S. aureus ATCC 25923 & $>32$ \\
\hline S. aureus ATCC 12600 & 32 \\
\hline S. aureus (methicillin resistant, clinical isolate 713623 ) & $>32$ \\
\hline K. pneumoniae АТСС 13883 & $>32$ \\
\hline K. pneumoniae $\mathrm{KpC}+001825971$ & $>32$ \\
\hline A. baumannii (clinical isolate 003326263 ) & $>32$ \\
\hline E. cloacae colistin resistant (clinical isolate 1383251) & $>32$ \\
\hline E. faecalis ATCC 19433 & $4-8$ \\
\hline P. aeruginosa ATCC 27853 & $>32$ \\
\hline P. aeruginosa PAO1 & 32 \\
\hline P. aeruginosa PA14 & 32 \\
\hline \multicolumn{2}{|l|}{ Hemolytic Activity (IC50) $(\mu \mathrm{M})$} \\
\hline human erythrocytes & $>100$ \\
\hline \multicolumn{2}{|l|}{ Cytotoxic Activity (IC50) $(\mu \mathrm{M})$} \\
\hline 3T3-L1 & $>100$ \\
\hline HUVECs & $>100$ \\
\hline human prostate cancer, $\mathrm{PC}-3$ & $>100$ \\
\hline human breast cancer, MCF-7 & $100^{b}$ \\
\hline human colon adenocarcinoma, HT-29 & $100^{b}$ \\
\hline
\end{tabular}

${ }^{a}$ MIC: minimal inhibitory concentration. IC50: half-maximum inhibitory concentration. ${ }^{b} 25 \%$ of cell viability decreased.

mised patients. ${ }^{11}$ Therefore, $P$. aeruginosa PAO1 was chosen here to perform the antibiofilm assays. ${ }^{12}$ Two-day-old $P$. aeruginosa PAO1 biofilms were grown in BM2 medium and subsequently treated with PaDBS1R6F10. PaDBS1R6F10 killed $P$. aeruginosa biofilm-constituting cells at a dose of 16 $\mu \mathrm{M}$ (Figure 1A). However, complete biofilm eradication was not observed (Figure 1B,C). Combinatorial approaches may be required to fully eliminate biofilms and prevent persister cell formation. A potential strategy may involve the use of AMPs in combination with antibiotics, which are known to synergize. $^{13,14}$ Additional strategies may include using AMPs in conjunction with molecules that degrade the extracellular polymeric substance (EPS) of biofilms and target both resident and persister microorganisms. ${ }^{2}$

Prior to in vivo studies, the cytotoxicity potential of PaDBS1R6F10 was evaluated against mammalian cells, ${ }^{15}$ including mouse adipocyte (3T3-L1) and human umbilical vein endothelial cells (HUVEC) (non-cancerous cells lines) and human prostate cancer cells (PC-3), human breast cancer cells (MCF-7), and human colon adenocarcinoma cells (HT29) (cancerous cell lines) (Table 2). PaDBS1R6F10 was not toxic against 3T3-L1, HUVEC, and PC-3 cell lines at concentrations up to $100 \mu \mathrm{M}$; however, a decrease of $25 \%$ in cell viability was observed against MCF-7 and HT-29 (Table 2). In addition, hemolytic assays showed that PaDBS1R6F10 was not hemolytic against healthy human erythrocytes at concentrations corresponding to 3.125-25-fold higher than the MIC, demonstrating the safety of the peptide and highlighting its potential for clinical development.

$P$. aeruginosa has been reported as a pathogen of major concern in skin injury infections, causing high mortality rates in care units. ${ }^{16}$ In addition, despite the use of top-of-the-line antibiotics, little success has been achieved thus far in terms of patient recovery. We therefore performed bacterial killing 
A

Control
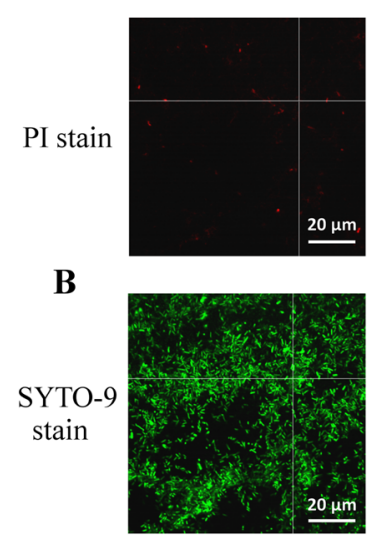

C

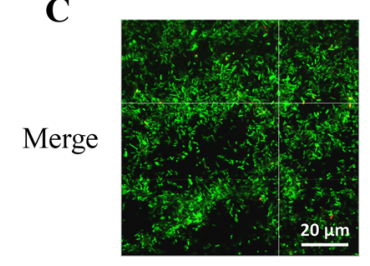

PaDBS1R6F10
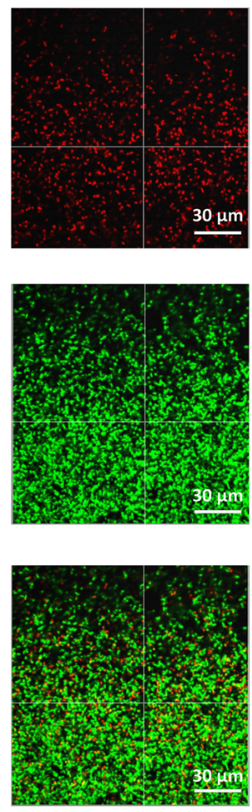

D

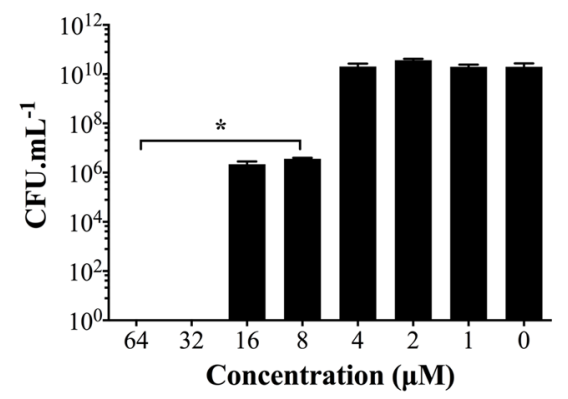

E

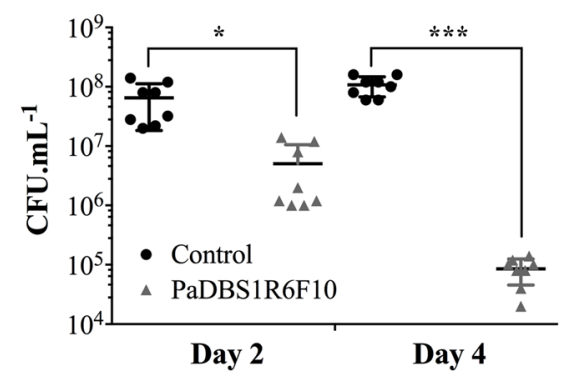

Figure 1. Flow cell analysis, bactericidal properties, and in vivo activity of PaDBS1R6F10. P. aeruginosa PAO1 biofilms were stained and visualized using SYTO-9 to stain live biofilm cells (green, live cells) and propidium iodide (PI) (red, dead cells). PAO1 biofilm untreated controls were compared with PAO1 biofilm treated with $16 \mu \mathrm{M}$ of PaDBS1R6F10, and the dead cells only (A), live cells only (B), and dead/live cells (C) were visualized. Scale bar $=20 \mu \mathrm{m}$ for controls; scale bar $=30 \mu \mathrm{m}$ for treatments. (D) Bactericidal activity in vitro of PaDBS1R6F10 against P. aeruginosa PA14 at doses ranging from 0 to $64 \mu \mathrm{M}\left({ }^{*} p>0.01\right.$ for 64 to $\left.8 \mu \mathrm{M}\right)$. (E) PaDBS1R6F10 in vivo activity against P. aeruginosa PA14 using a scarification skin infection mouse model $\left(64 \mu \mathrm{M}, 2\right.$-fold higher than the bactericidal concentration) $\left(*_{p}>0.01 ; * * * p>0.0001\right)$.

assays on $P$. aeruginosa PA14 grown in the presence of increasing concentrations of PaDBS1R6F10. The results obtained suggest that the peptide exhibited bactericidal properties against this particular bacterial strain at $32 \mu \mathrm{M}$ (Figure 1D). Further, in vivo assays using a scarification skin infection mouse model were carried out with $P$. aeruginosa PA14. PaDBS1R6F10 caused a gradual reduction of the bacterial load at $64 \mu \mathrm{M}$ (2-fold higher than its bactericidal concentration), reaching a maximum $10^{3} \mathrm{CFU} \cdot \mathrm{mL}^{-1}$ decrease at day four, compared to the untreated control groups (Figure $1 \mathrm{E})$.

The parent peptide (PaDBS1R6) ${ }^{8}$ used for PaDBS1R6F10 generation was recently evaluated in vivo using this same animal model, bacterial strain, and peptide concentration. As a result, PaDBS1R6 caused a $10^{3} \mathrm{CFU} \cdot \mathrm{mL}^{-1}$ decrease in $P$. aeruginosa counts 2 days post-infection. ${ }^{8}$ On the contrary, this anti-infective efficacy was not observed at day four, suggesting a time-dependent in vivo activity that might be related to peptide degradation events. ${ }^{8}$ It is known that AMP degradation in animal models still represents a bottleneck for the application of these antimicrobials in clinical practice. Here, we present a short, cationic, and linear AMP that has no chemical modifications to assist structural stability and that seems to be less susceptible to degradation events compared to its 19-amino acid residue parent peptide (considering the timedependent in vivo data). Interestingly, other studies have also shown similar findings, in which shorter AMPs present longterm effects in vivo due to higher enzymatic degradation resistance (less cleavage sites) when compared to larger wellknown AMPs, including magainin and buforin family members. ${ }^{17}$ Nevertheless, further studies regarding PaDBS1R6 and PaDBS1R6F10 enzymatic degradation susceptibility/ resistance are encouraged to confirm these hypotheses.
Cationic AMPs have been reported as a promising class of antimicrobial agents because of their broad-spectrum activity. ${ }^{18}$ Here, the short, cationic peptide PaDBS1R6F10 showed antimicrobial effects against Gram-positive and Gram-negative bacterial strains, including the drug-resistant clinical isolate E. coli $\mathrm{KpC}+$ at concentrations that have no negative effects on human cells. In addition, the peptide demonstrated antiinfective potential as it significantly reduced $P$. aeruginosa cell counts in a murine model of skin infections.

The structural conformations adopted by AMPs in contact with different bacterial targets are known to play a crucial role in the mechanism of action of these molecules. ${ }^{3}$ Here, we investigated the secondary structure of PaDBS1R6F10 by circular dichroism (CD) under different conditions, including hydrophilic (water/phosphate buffer), hydrophobic (water/ 2,2,2-trifluoroethanol (TFE) mixtures), and membrane-like (sodium dodecyl sulfate (SDS) micelles). PaDBS1R6F10 adopted random coil conformations in both water and buffer, as well as a weak $\alpha$-helical structure in TFE mixtures. However, a canonical spectral signature was observed in the last condition, indicating a well-defined $\beta$-sheet conformation when in contact with SDS micelles (Figure 2). Taken together, these findings reveal the high structural plasticity of PaDBS1R6F10, which may be related to its diverse biological activities. Indeed, other short cationic AMPs that adopt $\beta$-sheet conformations in an anionic environment have been reported as multifunctional peptides, presenting antimicrobial and antibiofilm properties, as well as endotoxin neutralizing activity (e.g., $(\text { IRIK })_{2}-\mathrm{NH}_{2},(\text { IRVK) })_{3}-\mathrm{NH}_{2}$, and $\left(\text { VRVK) }{ }_{3}-\mathrm{NH}_{2}\right)^{19,20}$ Moreover, short $\beta$-sheet AMPs have been commonly reported for their ability to aggregate in anionic conditions (e.g., SDS micelles), forming extended $\beta$-sheets that may trigger membrane-associated or intracellular mechanisms of action 


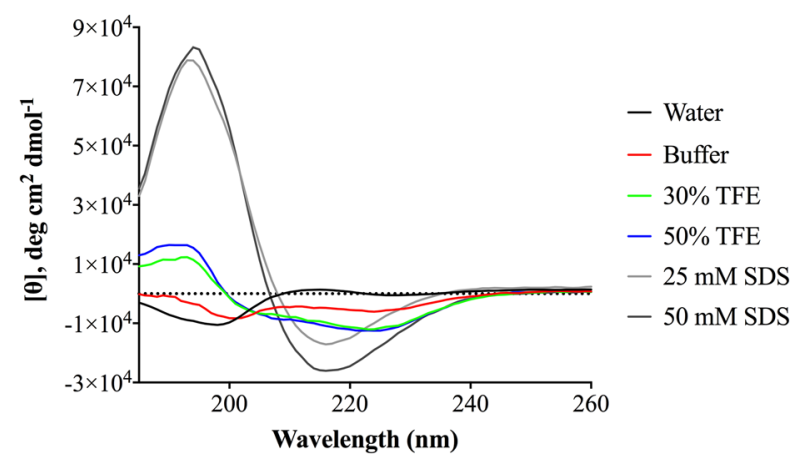

Figure 2. Structural characterization of peptide PaDBS1R6F10 by circular dichroism (CD). CD spectra of PaDBS1R6F10 in water, buffer (10 $\mathrm{mM} \mathrm{KH}_{2} \mathrm{PO}_{4}$ (pH 7.4)), 30\% and 50\% TFE (v/v), and 25 and $50 \mathrm{mM}$ SDS.

against bacteria. $^{21,22}$ On the basis of that, we may conclude that PaDBS1R6F10 conformational preference for anionic membrane-like environments might explain its selective biological potential toward bacteria. Nevertheless, detailed structural analyses are encouraged to better understand the role of PaDBS1R6F10 aggregation in its antibacterial activities and mode of action.

In summary, PaDBS1R6F10 was characterized as an antibacterial and antibiofilm peptide that does not exert toxic effects toward mammalian cells in vitro. We demonstrate the potential use of this peptide against clinically relevant bacterial strains including E. coli, S. aureus, E. faecalis, and P. aeruginosa, as well as antibiotic-resistant clinical isolates. Furthermore, this peptide compromised the viability of biofilm cells and showed a gradual decrease of $P$. aeruginosa cell viability when used as a treatment in a murine skin infection model. Moreover, a structural plasticity that was dependent on the environment was observed. The antimicrobial properties of synthetic peptide PaDBS1R6F10, in addition to its lack of toxicity toward mammalian cells, make PaDBS1R6F10 a potential therapeutic candidate for the treatment of bacterial infections.

\section{MATERIAL AND METHODS}

1. Peptide Design and Screening for Antibacterial Activity. Porto et al. ${ }^{6}$ used the non-redundant protein database (NR) as a library for the identification of potential candidate antimicrobial sequences according to the $\alpha$-helical pattern $(\mathrm{KK}[\mathrm{ILV}] \mathrm{x}(3)[\mathrm{AILV}]){ }^{6}$ From this analysis, the fragment (MARNKPLGKKLRLAAAFK) from $P$. aerophilum was identified and used as a template for automated rational design (the Joker algorithm), generating, among others, the peptide PaDBS1R6. ${ }^{6,8}$ Here, PaDBS1R6 was used as template for a sliding-window strategy (window size $=10$ ), which generated ten synthetic variants (PaDBS1R6F1 to PaDBS1R6F10). These variants were initially synthesized in the present study using the SPOT technology ${ }^{23}$ and submitted to initial antimicrobial/hemolytic screening, according to Hilpert and Hancock. ${ }^{24}$ Among the variants, the tenth fragment (PaDBS1R6F10-KKLRLKIAFK) presented higher antimicrobial potential with MIC of $20 \mu \mathrm{M}$ against a bioluminescent $P$. aeruginosa strain (Table 1 ) and, therefore, was selected for further investigation. For this, PaDBS1R6F10 was obtained from Peptide 2.0 Incorporated (USA), which synthesized the peptide at $95 \%$ purity by the stepwise solidphase method using the N-9-fluorenylmethyloxycarbonyl (Fmoc) strategy on a Rink amide resin.
2. Minimal Inhibitory Concentration (MIC) Assays against Planktonic Bacterial Cells. All the bacterial strains were grown on Mueller-Hinton agar (MHA) plates and incubated at $37^{\circ} \mathrm{C}$ for $18 \mathrm{~h}$. After the incubation time, three isolated colonies were chosen for each strain, inoculated into 5 $\mathrm{mL}$ of Mueller-Hinton broth (MHB), and incubated at $37{ }^{\circ} \mathrm{C}$ and $200 \mathrm{rpm}$ overnight. Bacterial growth was quantified by measuring the absorbance at $600 \mathrm{~nm}$ using a spectrophotometer. MIC assays were performed as described by Wiegand et al., ${ }^{10}$ with modifications, using broth microdilution in 96well round-bottom microplates. PaDBS1R6F10 antimicrobial potential was evaluated from 2 to $32 \mu \mathrm{M}$. Bacterial suspension $\left((2-5) \times 10^{5} \mathrm{CFU} \cdot \mathrm{mL}^{-1}\right)$ was used as negative control. Microplates were incubated at $37{ }^{\circ} \mathrm{C}$ during $18 \mathrm{~h}$. Bacterial growth inhibition was assessed by measuring the absorbance at $600 \mathrm{~nm}$ using a microplate reader (Bio-Tek Instruments). Three independent experiments were performed.

3. Biofilm Cultivation in Flow Chambers and Confocal Microscopy. Biofilms of the $P$. aeruginosa strain $\mathrm{PAO} 1$ were grown for $48 \mathrm{~h}$ at $37^{\circ} \mathrm{C}$ in flow chambers with channel dimensions of $1 \times 4 \times 40 \mathrm{~mm}$. BM2 medium [62 mmol $\mathrm{L}^{-1}$ potassium phosphate buffer, $\mathrm{pH} 7.0,7 \mu \mathrm{M}$ $\left.\left(\mathrm{NH}_{4}\right)_{2} \mathrm{SO}_{4}, 2 \mathrm{mmol} \mathrm{L} \mathrm{L}^{-1} \mathrm{MgSO}_{4}, 10 \mathrm{~mol} \cdot \mathrm{L}^{-1} \mathrm{FeSO}_{4}\right]$, containing $0.4 \%$ (wt/vol) glucose as a carbon source, was continuously flowed. Conditions and the experimental apparatus were previously described in detail by Reffuveille et $\mathrm{al}^{25}$ Two day-old biofilms were treated with peptide (16 $\mu \mathrm{M})$ for the following $12 \mathrm{~h}$. Biofilm cells were stained using a LIVE/DEAD BacLight bacterial viability kit (Syto-9 for green fluorescence of live cells and propidium iodide for red fluorescence of dead cells, 1:5, v/v) prior to the microscopy experiments. Microscopy was done using a confocal laser scanning microscope (Zeiss LSM 700 Laser Scanning Confocal), and three-dimensional reconstructions were generated using the Imaris software package (Bitplane AG). Two independent replicates for each condition were performed.

4. Cytotoxicity Assay. All the in vitro cytotoxicity experiments were performed as previously reported by Chan et al. $^{15}$ using human umbilical vein endothelial cells (HUVEC), Mus musculus adipocytes (3T3-L1), colon cancer cells (HT-29), breast cancer cells (MCF-7), and human prostate cancer cells (PC-3).

Cell cultures were maintained using the media conditions described above, where passages $2-10$ were used for all cell lines. Here, $5 \times 10^{3}$ cells per well $(100 \mu \mathrm{L})$ were used for both HUVECs and $3 \mathrm{~T} 3-\mathrm{L} 1$, and $2.5 \times 10^{3}$ cells per well $(100 \mu \mathrm{L})$ were used for the cancer cell lines. Cells were allowed to attach for $24 \mathrm{~h}$ after plating. Before the addition of PaDBS1R6F10, cells were treated with fresh media. After the addition of PaDBS1R6F10 (100, 50, 25, 12.5, 6.25, 3.125, 1.562, and $0.781 \mu \mathrm{M}$; final concentration per well), cells were incubated for $2 \mathrm{~h}$. Moreover, $0.1 \%(\mathrm{v} / \mathrm{v})$ Triton X-100 was used as positive control. To evaluate cell viability 3-(4,5-dimethylthiazolyl-2)-2,5-diphenyltetrazolium bromide (MTT) (5 mg. $\mathrm{mL}^{-1}$ in PBS) was added after $2 \mathrm{~h}$ of incubation. Thereafter, cells were incubated for an additional $4 \mathrm{~h}$. The supernatants were then removed, and $100 \mu \mathrm{L}$ of DMSO was added to solubilize formazan salts. Experiments were performed in triplicate. Cell numbers were measured at $600 \mathrm{~nm}$ using a microplate reader (BioTek PowerWave XS).

5. Hemolytic Assay. Human red blood cells were used to measure the hemolytic effect of PaDBS1R6F10 at 100, 50, 25, $12.5,6.25,3.125,1.562$, and $0.781 \mu \mathrm{M}$. The antimicrobial 
peptide melittin was used as positive control following 2-fold dilutions starting from $20 \mu \mathrm{M}$ (final concentration per well). In addition, $1 \%(\mathrm{v} / \mathrm{v})$ Triton X-100 and erythrocytes in PBS were used as positive and negative controls, respectively. Sample absorbance was measured at $415 \mathrm{~nm}$ using a microplate reader (BioTek PowerWave XS). Experiments were performed in triplicates.

6. Bacterial Killing Experiments. A killing experiment was performed with 1:100 dilutions of overnight cultures of $P$. aeruginosa PA14 in the absence or presence of increasing concentrations of PaDBS1R6F10 $(0-64 \mu \mathrm{M})$. After $24 \mathrm{~h}$ of treatment, 10-fold serial dilutions were performed; bacteria were plated on Pseudomonas Isolation Agar and allowed to grow overnight at $37{ }^{\circ} \mathrm{C}$, after which colony-forming unit (CFU) counts were recorded. Three independent experiments were performed.

7. Scarification Skin Infection Mouse Model. P. aeruginosa strain PA14 was grown to an optical density at $600 \mathrm{~nm}$ of 0.5 in tryptic soy broth (TSB) medium. Subsequently, cells were washed twice with sterile PBS ( $\mathrm{pH} 7.4,13000 \mathrm{rpm}$ for 1 $\mathrm{min}$ ) and resuspended to a final concentration of $5 \times 10^{6} \mathrm{CFU}$. $20 \mu \mathrm{L}^{-1}$. Skin infection was established according to Cardoso et al. ${ }^{26}$ One day after the infection, $64 \mu \mathrm{M}$ of PaDBS1R6F10 was administered to the infected area. Animals were euthanized 2 or 4 days postinfection, and the area of scarified skin $\left(\sim 1 \mathrm{~cm}^{2}\right)$ was excised and suspended in $1 \mathrm{~mL}$ of PBS. The excised skin sample was then homogenized using a bead beater for $20 \mathrm{~min}(25 \mathrm{~Hz})$ and serially diluted for CFU quantification. Two independent experiments were performed with 4 mice per group in each condition. Statistical significance was assessed using a one-way ANOVA, followed by Dunnett's test. Animals were maintained in accordance with the Guide for the Care and Use of Laboratory Animals in an AAALAC-accredited facility. All procedures were approved by the MIT's Institutional Animal Care and Use Committee (IACUC), protocol number 1016-064-19.

8. Structural Analysis. The PaDBS1R6F10 secondary structure was characterized as described by Cardoso et al., ${ }^{27}$ using a Jasco J-810 spectropolarimeter. PaDBS1R6F10 was prepared at $50 \mu \mathrm{M}$ in different solutions, including ultrapure water, $10 \mathrm{mM} \mathrm{KH}{ }_{2} \mathrm{PO}_{4}(\mathrm{pH} 7.4)$, 2,2,2-trifluoroethanol (TFE) mixtures $(30 \%$ and $50 \%(\mathrm{v} / \mathrm{v})$ in water), and sodium dodecyl sulfate (SDS) micelles (25 and $50 \mathrm{mM}$ ). Spectra were recorded at room temperature in $0.1 \mathrm{~cm}$ path length quartz cells. Five scans were accumulated for each sample from 185 to $260 \mathrm{~nm}$ at a scan speed of $50 \mathrm{~nm} \cdot \mathrm{min}^{-1}$.

\section{AUTHOR INFORMATION}

\section{Corresponding Author}

*Phone: +55 061 34487120. E-mail: ocfranco@gmail.com. ORCID 1

Marlon H. Cardoso: 0000-0001-6676-5362

Lai Y. Chan: 0000-0002-9346-2487

Karen G. N. Oshiro: 0000-0002-8813-6433

Evan F. Haney: 0000-0003-3645-770X

Timothy K. Lu: 0000-0002-3918-8923

Cesar de la Fuente-Nunez: 0000-0002-2005-5629

David J. Craik: 0000-0003-0007-6796

Octávio L. Franco: 0000-0001-9546-0525

\section{Present Address}

${ }^{\alpha}$ M.D.T.T. and C.F.-N.: Department of Psychiatry, and Department of Microbiology, Perelman School of Medicine,
University of Pennsylvania, Philadelphia, PA 19104, United States

\section{Author Contributions}

${ }^{\#}$ E.S.C. and M.H.C. contributed equally to this work. W.F.P. performed the in silico selection of peptides. S.R.M., E.F.H., and R.E.W.H. performed the preliminary experiments with luminescent $P$. aeruginosa. E.S.C., M.H.C., and K.G.N.O. performed the antibacterial experiments. M.D.T.T., C.F.-N., and T.K.L. performed the antibiofilm and in vivo scarification experiments. E.S.C., M.H.C., and L.Y.C. performed the structural analyses. E.S.C. and M.H.C. wrote and organized the paper with input from all authors. D.J.C. and O.L.F. supervised and reviewed this work. All authors reviewed this paper.

\section{Notes}

The authors declare no competing financial interest.

${ }^{\beta}$ M.D.T.T.: Department of Bioengineering, University of Pennsylvania, Philadelphia, PA 19104, US, United States

\section{ACKNOWLEDGMENTS}

This work was supported by grants from Coordenação de Aperfeiçoamento de Pessoal de Nivel Superior (CAPES) (to M.H.C. 88881.134423/2016-01), Conselho Nacional de Desenvolvimento e Tecnológico (CNPq) (to M.H.C. 141518/2015-4), Fundação de Apoio ao Desenvolvimento do Ensino, Ciência e Tecnologia do Estado de Mato Grosso do Sul (FUNDECT), Brazil, Fundação de Apoio à Pesquisa do Distrito Federal (FAPDF), Ramon Areces Foundation (to C.F.-N.), DTRA (DTRA HDTRA1-15-1-0050) (to T.K.L.), and Fundação de Amparo à Pesquisa do Estado de São Paulo (M.D.T.T. \# 2014/04507-5 and 2016/24413-0). D.J.C. is an ARC Australian Laureate Fellow (FL150100146). L.Y.C. was supported by the Advance Queensland Women's Academic Fund (WAF-6884942288). R.E.W.H. holds a Canada Research Chair. We thank Robin Kramer for her assistance with the skin scarification mouse model.

\section{ABBREVIATIONS}

AMPs, antimicrobial peptides; KpC, Klebsiella pneumoniae carbapenemase; TFE, 2,2,2-trifluoroethanol; SDS, sodium dodecyl sulfate; MIC, minimal inhibitory concentration; HUVEC, human umbilical vein endothelial cells; 3T3-L1, mouse adipocyte; PC-3, human prostate cancer cells; MCF-7, human breast cancer cells; HT-29, human colon adenocarcinoma cells

\section{REFERENCES}

(1) Haney, E. F., Brito-Sanchez, Y., Trimble, M. J., Mansour, S. C., Cherkasov, A., and Hancock, R. E. W. (2018) Computer-aided discovery of peptides that specifically attack bacterial biofilms. Sci. Rep. 8, 1871.

(2) Koo, H., Allan, R. N., Howlin, R. P., Stoodley, P., and HallStoodley, L. (2017) Targeting microbial biofilms: current and prospective therapeutic strategies. Nat. Rev. Microbiol. 15, 740-755.

(3) Lee, T. H., Hall, K. N., and Aguilar, M. I. (2015) Antimicrobial peptide structure and mechanism of action: A focus on the role of membrane structure. Curr. Top. Med. Chem. 16, 25-39.

(4) Wiradharma, N., Sng, M. Y., Khan, M., Ong, Z. Y., and Yang, Y. Y. (2013) Rationally designed $\alpha$-helical broad-spectrum antimicrobial peptides with idealized facial amphiphilicity. Macromol. Rapid Commun. 34, 74-80.

(5) Fjell, C. D., Hiss, J. A., Hancock, R. E., and Schneider, G. (2012) Designing antimicrobial peptides: form follows function. Nat. Rev. Drug Discovery 11, 37-51. 
(6) Porto, W. F., Fensterseifer, I. C. M., Ribeiro, S. M., and Franco, O. L. (2018) Joker: An algorithm to insert patterns into sequences for designing antimicrobial peptides. Biochim. Biophys. Acta, Gen. Subj. 1862, 2043-2052.

(7) Wang, G., Li, X., and Wang, Z. (2016) APD3: the antimicrobial peptide database as a tool for research and education. Nucleic Acids Res. 44, D1087-1093.

(8) Fensterseifer, I. C. M., Felicio, M. R., Alves, E. S. F., Cardoso, M. H., Torres, M. D. T., Matos, C. O., Silva, O. N., Lu, T. K., Freire, M. V., Neves, N. C., Goncalves, S., Liao, L. M., Santos, N. C., Porto, W. F., de la Fuente-Nunez, C., and Franco, O. L. (2019) Selective antibacterial activity of the cationic peptide PaDBS1R6 against Gramnegative bacteria. Biochim. Biophys. Acta, Biomembr., DOI: 10.1016/ j.bbamem.2019.03.016.

(9) Micek, S. T., Hampton, N., and Kollef, M. (2018) Risk factors and outcomes for ineffective empiric treatment of sepsis caused by gram-negative pathogens: Stratification by onset of infection. Antimicrob. Agents Chemother. 62, e01577-01517.

(10) Wiegand, I., Hilpert, K., and Hancock, R. E. (2008) Agar and broth dilution methods to determine the minimal inhibitory concentration (MIC) of antimicrobial substances. Nat. Protoc. 3, $163-175$.

(11) El Chakhtoura, N. G., Saade, E., Iovleva, A., Yasmin, M., Wilson, B., Perez, F., and Bonomo, R. A. (2018) Therapies for multidrug resistant and extensively drug-resistant non-fermenting gram-negative bacteria causing nosocomial infections: a perilous journey toward 'molecularly targeted' therapy. Expert Rev. Anti-Infect. Ther. 16, 89-110.

(12) de la Fuente-Nunez, C., Korolik, V., Bains, M., Nguyen, U., Breidenstein, E. B., Horsman, S., Lewenza, S., Burrows, L., and Hancock, R. E. (2012) Inhibition of bacterial biofilm formation and swarming motility by a small synthetic cationic peptide. Antimicrob. Agents Chemother. 56, 2696-2704.

(13) Ribeiro, S. M., de la Fuente-Nunez, C., Baquir, B., Faria-Junior, C., Franco, O. L., and Hancock, R. E. (2015) Antibiofilm peptides increase the susceptibility of carbapenemase-producing Klebsiella pneumoniae clinical isolates to $\beta$-lactam antibiotics. Antimicrob. Agents Chemother. 59, 3906-3912.

(14) de la Fuente-Nunez, C., Cardoso, M. H., de Souza Candido, E., Franco, O. L., and Hancock, R. E. (2016) Synthetic antibiofilm peptides. Biochim. Biophys. Acta, Biomembr. 1858, 1061-1069.

(15) Chan, L. Y., Zhang, V. M., Huang, Y. H., Waters, N. C., Bansal, P. S., Craik, D. J., and Daly, N. L. (2013) Cyclization of the antimicrobial peptide gomesin with native chemical ligation: influences on stability and bioactivity. ChemBioChem 14, 617-624.

(16) Sousa Dominguez, A., Perez-Rodriguez, M. T., Nodar, A., Martinez-Lamas, L., Perez-Landeiro, A., and Crespo Casal, M. (2016) Successful treatment of MDR Pseudomonas aeruginosa skin and softtissue infection with ceftolozane/tazobactam. J. Antimicrob. Chemother. 72, 1262-1263.

(17) Kim, H., Jang, J. H., Kim, S. C., and Cho, J. H. (2014) De novo generation of short antimicrobial peptides with enhanced stability and cell specificity. J. Antimicrob. Chemother. 69, 121-132.

(18) Bormann, N., Koliszak, A., Kasper, S., Schoen, L., Hilpert, K., Volkmer, R., Kikhney, J., and Wildemann, B. (2017) A short artificial antimicrobial peptide shows potential to prevent or treat bone infections. Sci. Rep. 7, 1506.

(19) Ong, Z. Y., Gao, S. J., and Yang, Y. Y. (2013) Short synthetic $\beta$ sheet forming peptide amphiphiles as broad spectrum antimicrobials with antibiofilm and endotoxin neutralizing capabilities. Adv. Funct. Mater. 23, 3682-3692.

(20) Zhong, G., Cheng, J., Liang, Z. C., Xu, L., Lou, W., Bao, C., Ong, Z. Y., Dong, H., Yang, Y. Y., and Fan, W. (2017) Short synthetic $\beta$-sheet antimicrobial peptides for the treatment of multidrug-resistant Pseudomonas aeruginosa burn wound infections. Adv. Healthcare Mater. 6, 1601134.

(21) Manzo, G., Scorciapino, M. A., Wadhwani, P., Burck, J., Montaldo, N. P., Pintus, M., Sanna, R., Casu, M., Giuliani, A., Pirri, G., Luca, V., Ulrich, A. S., and Rinaldi, A. C. (2015) Enhanced amphiphilic profile of a short $\beta$-stranded peptide improves its antimicrobial activity. PLoS One 10, No. e0116379.

(22) Phambu, N., Almarwani, B., Garcia, A. M., Hamza, N. S., Muhsen, A., Baidoo, J. E., and Sunda-Meya, A. (2017) Chain length effect on the structure and stability of antimicrobial peptides of the (RW)n series. Biophys. Chem. 227, 8-13.

(23) Winkler, D. F., Hilpert, K., Brandt, O., and Hancock, R. E. (2009) Synthesis of peptide arrays using SPOT-technology and the CelluSpots-method. Methods Mol. Biol. 570, 157-174.

(24) Hilpert, K., and Hancock, R. E. (2007) Use of luminescent bacteria for rapid screening and characterization of short cationic antimicrobial peptides synthesized on cellulose using peptide array technology. Nat. Protoc. 2, 1652-1660.

(25) Reffuveille, F., de la Fuente-Nunez, C., Mansour, S., and Hancock, R. E. (2014) A broad-spectrum antibiofilm peptide enhances antibiotic action against bacterial biofilms. Antimicrob. Agents Chemother. 58, 5363-5371.

(26) Cardoso, M. H., Candido, E. S., Chan, L. Y., Torres, M. T., Oshiro, K. G. N., Rezende, S. B., Porto, W. F., Lu, T. K., de la FuenteNunez, C., Craik, D. J., and Franco, O. L. (2018) A computationally designed peptide derived from Escherichia coli as a potential drug template for antibacterial and antibiofilm therapies. ACS Infect. Dis. 4, $1727-1736$.

(27) Cardoso, M. H., Ribeiro, S. M., Nolasco, D. O., de la FuenteNunez, C., Felicio, M. R., Goncalves, S., Matos, C. O., Liao, L. M., Santos, N. C., Hancock, R. E., Franco, O. L., and Migliolo, L. (2016) A polyalanine peptide derived from polar fish with anti-infectious activities. Sci. Rep. 6, 21385. 